\title{
5-Arylazo-2,2'-bithiophenes: a Novel Promising Series of NLO Chromophores
}

\author{
M. Manuela M. Raposo, ${ }^{1, a^{\star}}$ Ana M. Ferreira, ${ }^{1, b}$ M. Belsley, ${ }^{2, c}$ E. de Matos \\ Gomes $^{2, d}$ and J. C. V. P. Moura ${ }^{1,}$
}

\author{
${ }^{1}$ Centro de Química, Universidade do Minho, Campus de Gualtar \\ 4710-057 Braga, Portugal \\ ${ }^{2}$ Departamento de Física, Universidade do Minho, Campus de Gualtar \\ 4710-057 Braga, Portugal \\ a,b mfox@quimica.uminho.pt, belsley@fisica.uminho.pt, \\ emg@fisica.uminho.pt, moura@quimica.uminho.pt
}

\begin{abstract}
Keywords: Azo dyes, heterocycles, Bithiophenes, Donor-acceptor conjugated systems, UV-visible spectroscopy, solvatochromism, Nonlinear optics (NLO), hyper-Rayleigh scattering technique
\end{abstract}

\begin{abstract}
The synthesis of 5-arylazo- substituted bithiophenes and their UV-visible, solvatochromic and nonlinear optical properties (NLO) are described. In agreement with the solvatochromic data and also with the second-order molecular NLO characterization, the new donor-acceptor systems could find application as suitable solvatochromic probes and also as new NLO materials.
\end{abstract}

\section{Introduction}

During the past decade, heteroaromatic compounds have attracted widespread interest because it was experimentally [1] and theoretically [2] demonstrated that they increase the second-order molecular NLO properties of push-pull chromophores with respect to the corresponding aryl analogues. They have great potential especially for use in optical communication, information processing, frequency doubling and integrated optics [3]. In fact, since the delocalization energy of heteroaromatics, such as thiophene, pyrrole and thiazole is lower than that of benzene, their presence in push-pull chromophores is expected to result in enhanced charge transfer properties [4] and NLO responses, in comparison with related systems containing benzenoid rings. Thus, one of the most recent approaches to the design of highly NLO-active systems is based on the presence of a five-member heterocyclic ring in a push-pull donor-acceptor chromophore. Moreover, heterocyclic based chromophores appear to be more easily processed compared to more extended conjugated compounds containing benzenoid rings, which are often insoluble in common organic solvents. Accordingly, recent trends in tailoring second order nonlinear materials deal with pushpull chromophores with relatively short conjugated paths containing heterocycles [5-13]. A renewed interest in aryl(heteroaryl)-azo dyes has been sparked by efforts to find organic secondorder non-linear optical (NLO) materials suitable for applications such as harmonic generation and optical switching. Azo dyes are of particular interest because they can be readily prepared with a wide range of donor and acceptor groups and also because the planarity of the azo bridge versus the nonplanarity of stilbenes or other systems should contribute to the larger $\pi$ electron transmission effects and lead to higher optical activity [14-15]. As part of our continuing interest in solvatochromic, non-linear optical [4-13] and photochromic [16] materials we report in this paper the synthesis, the solvatochromic and the nonlinear optical studies of new 5-arylazo-2,2'bithiophenes 3-5 which have the meta $\mathrm{CO}_{2} \mathrm{H}$ or para $\mathrm{CN}$ and $\mathrm{NO}_{2}$ groups as the electronwithdrawing groups on the phenylazo moiety and the conjugated 5-alkoxy-2,2'-bithiophenes, as strong $\pi$-electron donor moieties. 


\section{Results and discussion}

Synthesis. Recently we have reported the synthesis of 5-alkoxy-2,2'-bithiophenes 1 through a combination of the Friedel-Crafts and the Lawesson reactions [17]. Compounds 1 have proved to be versatile substrates in azo coupling reactions, allowing the preparation of several new donoracceptor substituted bithiophenes. The coupling reaction of aryldiazonium salts $2 a-c$, with bithiophenes $1 a-b$, in acetonitrile/acetic acid for $2 \mathrm{~h}$ at $0{ }^{\circ} \mathrm{C}$, give rise to the formation of bithiophene azo dyes 3-5. Diazo coupling was made selectively at the $5^{\prime}$-position of bithiophene moiety to give compounds 3-5 in moderate to good yields (27-48\%), (Scheme 1, Table 1). These results are in accordance with the selectivity of the reaction of electrofiles with 5-alkoxy-2,2'-bithiophenes as it has been shown earlier in the case of formylation and tricyanovinylation reactions [5]. The structures of bithiophenee azo dyes 3-5 were unambiguously confirmed by their analytical and spectral data.<smiles>[R]c1ccc(-c2ccc(N=Nc3ccc([N+](=O)[O-])cc3)s2)s1</smiles>

Table 1- Yields and UV-visible data of bithiophenes $1 a-b$ and bithiophene azo dyes 3-5.

\begin{tabular}{|c|c|c|c|c|c|c|c|}
\hline Entry & Bithiophene & $\begin{array}{c}\lambda_{\max } *[\mathrm{~nm}] \\
(\varepsilon)\end{array}$ & $\begin{array}{c}\text { Diazonium } \\
\text { salt }\end{array}$ & $\begin{array}{c}\text { Azo } \\
\text { bithiophene }\end{array}$ & $\mathrm{R}$ & $\begin{array}{c}\text { Yield } \\
{[\%]}\end{array}$ & $\begin{array}{c}\lambda_{\max } *[\mathrm{~nm}] \\
(\varepsilon)\end{array}$ \\
\hline 1 & $1 a$ & $\begin{array}{c}319.0 \\
(14,994)\end{array}$ & $2 a$ & $3 a$ & $\mathrm{MeO}$ & 37 & $\begin{array}{c}496.0 \\
(23,300)\end{array}$ \\
\hline 2 & $1 b$ & $\begin{array}{c}319.5 \\
(14,517)\end{array}$ & $2 a$ & $3 b$ & $\mathrm{EtO}$ & 48 & $\begin{array}{c}499.0 \\
(22,960)\end{array}$ \\
\hline 3 & $1 a$ & ----- & $2 b$ & $4 a$ & $\mathrm{MeO}$ & 27 & $\begin{array}{c}509.0 \\
(20,240)\end{array}$ \\
\hline 4 & $1 a$ & ----- & $2 c$ & $5 a$ & $\mathrm{MeO}$ & 47 & $\begin{array}{c}467.0 \\
(21,260)\end{array}$ \\
\hline 5 & $1 b$ & ----- & $2 c$ & $5 b$ & $\mathrm{EtO}$ & 48 & $\begin{array}{c}471.5 \\
(24,020)\end{array}$ \\
\hline
\end{tabular}

*All the UV/vis. spectra were run in ethanol.

$\boldsymbol{U V}$-visible study. Electronic absorption spectra of all push-pull compounds 3-5 show an intense lowest energy charge-transfer absorption band in the UV-visible region. The position of this band is 
strongly influenced by the structure of the compounds, for example by the type of substitution pattern in the donor and the acceptor moieties. Dramatic differences in energy occur upon arylazo substitution of bithiophenes 1. For example, bithiophene $1 a\left(\lambda_{\max }=319.0 \mathrm{~nm}\right)$ is shifted $190.0 \mathrm{~nm}$ upon arylazo substitution (bithiophene azo dye $4 a, \lambda_{\max }=509.0 \mathrm{~nm}$ ) (Table 1 entries 1 and 3 respectively). The influence of the strength of the acceptor group substituted on the arylazo moiety is demonstrated by comparison of the absorption maxima of compounds $5 a$ and $4 a$ as the longest wavelength transition is shifted from $467.0 \mathrm{~nm}$ in azo-bithiophene $5 a$ to $509.0 \mathrm{~nm}$ for azobithiophene $4 a$ (Table 1, entries 4 and 3 respectively). This effect has been attributed to the stabilization of LUMO by the electron-withdrawing groups [4]. The influence of the electronic nature of the substituent at 5-position on the bithiophene moiety is demonstrated by comparison of the absorption maxima of compounds $3 a$ and $3 b$ as the longest wavelength transition is shifted from $496 \mathrm{~nm}$ in azo dye $3 a$ to $499 \mathrm{~nm}$ for azo dye $3 b$ (Table 1, entries 1 and 2 respectively). In general, the stronger the donor and/or acceptor group, the smaller the energy difference between ground and excited states, and the longer the wavelength of absorption. The increase of the $\beta$ values characteristic of the NLO effects is accompanied by an increase of the $\lambda_{\max }$ in the UV-visible spectra, i.e. a decrease in the intramolecular charge transfer (ICT) values [4].

Solvatochromic study. Heterocyclic azo dyes composed by pyrrole and thiophene moieties have been known to demonstrate strong solvatochromic behavior [7, 14]. To evaluate the intermolecular forces between the solvents and the solute molecules and in order to determine the best indicator dye, we made a preliminary study of the absorption spectra of compounds 3-5 in 5 selected solvents of different solvatation character (ethanol, THF, acetone, DMF and DMSO). For all azo dyes the highest energy transitions were found with nonpolar solvents such as hexane. More polar solvents such as DMSO resulted in lower energy transitions. This behavior has been defined as a positive solvatochromic response that is related to a greater stabilization of the excited state relative to the ground state with increasing polarity of the solvent. Moreover, compounds $3 a\left(\Delta v_{\max }=928 \mathrm{~cm}^{-1}\right)$, $5 a\left(\Delta v_{\max }=922 \mathrm{~cm}^{-1}\right)$ and $5 b\left(\Delta v_{\max }=1022 \mathrm{~cm}^{-1}\right)$, showed the longest shifts in wavenumber maxima. Therefore, $5 b$ was submitted to a full solvatochromic study involving 13 solvents (Table $2)$. Because of the pronounced solvatochromism, $\left(\Delta v_{\max }=+1281 \mathrm{~cm}^{-1}\right)$, the good correlation with $\pi^{*}$ values for the 13 solvents investigated $(r=0.9981)$ and the long wavelength absorption in the visible range, $5 b$ seemed to be a very appropriate solvent polarity indicating dye.

Table 2- Solvatochromic data $\left[\lambda_{\max }(\mathrm{nm})\right.$ and $v_{\max }\left(\mathrm{cm}^{-1}\right)$ of the charge-transfer band] for azo dye $5 b$ in 13 solvents in comparison with $\pi^{*}$ values by Kamlet and Taft [18]

\begin{tabular}{cccc}
\hline Solvents $^{\mathrm{a}}$ & $\pi^{*}$ & \multicolumn{2}{c}{ Compound $5 b$} \\
& & $\lambda_{\max }[\mathrm{nm}]$ & $v_{\max }\left[\mathrm{cm}^{-1}\right]$ \\
\hline$n$-hexane & -0.008 & 457.5 & 21,857 \\
diethyl ether & 0.27 & 461.0 & 21,691 \\
toluene & 0.54 & 474.5 & 21,074 \\
ethanol & 0.54 & 471.5 & 21,208 \\
dioxane & 0.55 & 471.0 & 21,231 \\
ethyl acetate & 0.55 & 469.0 & 21,321 \\
tetrahydrofuran & 0.58 & 474.0 & 21,180 \\
acetone & 0.71 & 463.0 & 21,598 \\
acetonitrile & 0.75 & 473.5 & 21,119 \\
chloroform & 0.76 & 475.0 & 21,052 \\
dichloromethane & 0.82 & 480.5 & 20,811 \\
dimethylformamide & 0.88 & 481.5 & 20,768 \\
dimethylsulfoxide & 1.00 & 486.0 & 20,576 \\
\hline
\end{tabular}

${ }^{a}$ Solvent used as received. 
Nonlinear optical study. We have used the hyper-Rayleigh scattering (HRS) method [19-20] to measure the first hyperpolarizability $\beta$ of azobithiophenes $3-5 \cdot p$-Nitroaniline ( $p$ NA) was used as standard [21-22] in order to obtain quantitative values (Table 3 ). The static hyperpolarisability $\beta_{0}$ values are calculated using a very simple two-level model neglecting damping. They are therefore only indicative and should be treated with caution. The experimental results obtained for the nonlinearieties $\beta$ of compounds $3 a$ and $4 a$ shows that, the increase of the acceptor strength of the group substituted at the para position of the aryl ring: $\left(\mathrm{CN}\right.$ and $\left.\mathrm{NO}_{2}\right)$ results in enhanced $\beta$ values for azobithiophenes $3 a-4 a$ compared to compound $5 a$ having a $\mathrm{CO}_{2} \mathrm{H}$ group in meta position (Table 3 , entries 1 and 3-4 respectively). Comparison of the $\beta$ values for the azo derivatives containing a methoxyl group substituted at the 5-position of the bithiophene donor moiety ( $3 a$ and $5 a$ ) leads to larger nonlinearities than the substitution by the etoxyl group at the same position of the bithiophene units ( $3 b$ and $5 b$ ). Azo dyes 3-5 exhibit high molecular nonlinearities as their values are 13-16 times higher that the well known $p$ NA molecule.

Table 3- Linear ${ }^{\mathrm{a}}$ and nonlinear optical ${ }^{\mathrm{a}}$ data of bithiophene azo dyes 3-5.

\begin{tabular}{ccccc}
\hline Entry & $\begin{array}{c}\text { Azo } \\
\text { bithiophene }\end{array}$ & $\begin{array}{c}\lambda_{\max } \\
{[\mathrm{nm}]}\end{array}$ & $\begin{array}{c}\beta^{\mathrm{b}} / 10^{-30} \\
{[\mathrm{esu}]}\end{array}$ & $\begin{array}{c}\beta_{0}{ }^{\mathrm{c}} / 10^{-30} \\
{[\mathrm{esu}]}\end{array}$ \\
\hline 1 & $3 a$ & 494.5 & 270 & 29 \\
2 & $3 b$ & 497.0 & 260 & 26 \\
3 & $4 a$ & 505.5 & 260 & 20 \\
4 & $5 a$ & 468.5 & 240 & 43 \\
5 & $5 b$ & 472.5 & 220 & 37 \\
6 & $p \mathrm{NA}$ & 352.0 & $16.9[21-22]$ & 8,5 \\
\hline
\end{tabular}

${ }^{a}$ Experimental hyperpolarizabilities and spectroscopic data measured in dioxane solutions. ${ }^{\mathrm{b}}$ All the compounds are transparent at the $1064 \mathrm{~nm}$ fundamental wavelenght. ${ }^{c}$ Data corrected for ressonance enhancement at $532 \mathrm{~nm}$ using the two-level model with $\beta_{0}=\beta\left[1-\left(\lambda_{\max } / 1064\right)^{2}\right]\left[1-\left(\lambda_{\max } / 532\right)^{2}\right]$; damping factors not included $1064 \mathrm{~nm}[23-25]$.

\section{Conclusions}

In summary, we have achieved the first synthesis of a series of bithienyl azo dyes 3-5 in moderate to good yields. By comparing the several derivatives synthesized, it can be seen that the withdrawing group on the phenylazo moiety and the type of substituent on the 5-position of the bithienyl moiety have significant influence on the solvatochromic and the nonlinear optical properties. These derivatives exhibit dramatic changes in both their electronic and optical properties in comparison to the unsubstituted 5-alkoxy-bithiophenes 1 . In agreement with the solvatochromic and the nonlinear optical studies of push-pull derivatives 3-5 and also with previous findings the new compounds prepared, can find application for manufacturing new materials with good photochromic [16] and non-linear optical properties [7, 26].

\section{Acknowledgements}

Thanks are due to Foundation for Science and Technology (Portugal) for financial support through Center of Chemistry and Department of Physics at the University of Minho. 


\section{References}

[1] E.M. Breitung, C.-F. Shu and R.J. McMahon: J. Am. Chem. Soc. Vol. 122 (2000), p. 1154.

[2] A. Facchetti, A. Abbotto, L. Beverina, M.E. van der Boom, P. Dutta, G. Evmenenko, T.J. Marks and G.A. Pagani: Chem. Mat. Vol. 14 (2002), p. 4996.

[3] D.R. Kanis, M.A. Ratner and T.J. Marks: Chem. Rev. Vol. 94 (1994), p. 195.

[4] M.M. Oliva, J. Casado, M.M.M. Raposo, A.M.C. Fonseca, H. Hartmann, V. Hernandez and J.T.L. Navarrete: J. Org. Chem. Vol. 71 (2006), p. 7509.

[5] M.M.M. Raposo and G. Kirsch: Tetrahedron Vol. 59 (2003), p. 4891.

[6] M.M.M. Raposo, A.M.C. Fonseca and G. Kirsch: Tetrahedron Vol. 60 (2004), p. 4071.

[7] M.M.M. Raposo, A.M.R.C. Sousa, A.M.C. Fonseca and G. Kirsch: Tetrahedron Vol. 61 (2005), p. 8249.

[8] M.M.M. Raposo, A.M.R.C. Sousa, G. Kirsch, F. Ferreira, M. Belsley, E. Matos Gomes and A.M.C. Fonseca: Tetrahedron Vol. 61 (2005), p. 11991.

[9] M.M.M. Raposo, A.M.R.C. Sousa, G. Kirsch, P. Cardoso, M. Belsley, E. Matos Gomes and A.M.C. Fonseca: Org. Lett. Vol. 8 (2006), p. 3681.

[10] M.M.M. Raposo, A.M.R.C. Sousa, G. Kirsch and A.M.C. Fonseca: Tetrahedron Vol. 62 (2006), p. 3493.

[11] R.M.F. Batista, S.P.C. Costa and M.M.M. Raposo: Tetrahedron Lett. Vol. 45 (2004), p. 2825.

[12] R.M.F. Batista, S.P.C. Costa, P. Cardoso, M. Belsley and M.M.M. Raposo: Eur. J. Org. Chem. Vol. 17 (2006), p. 3938.

[13] R.M.F. Batista, S.P.C. Costa, M. Belsley and M.M.M. Raposo: Tetrahedron Vol. 63 (2007), p. 4258.

[14] A.D. Towns: Dyes Pigments Vol. 42 (1999), p. 3 and references cited therein.

[15] S.K. Yesodha, C.K.S. Pillai and N. Tsutsumi: Prog. Polym. Sci. Vol. 29 (2004), p. 45.

[16] P.J. Coelho, L.M. Carvalho, A.M.C. Fonseca and M.M.M. Raposo: Tetrahedron Lett. Vol 47 (2006), p. 3711.

[17] M.M.M. Raposo and G. Kirsch: Heterocycles Vol. 55 (2001), p. 1487.

[18] M.J. Kamlet, J.-L.M. Abboud, M.H. Abraham and R.W. Taft: J. Org. Chem. Vol. 48 (1983), p. 2877 and references cited therein.

[19] K. Clays and A. Persoons: Rev. Sci. Instrum. Vol. 63 (1992), p. 3285.

[20] K. Clays and A. Persoons: Phys. Rev. Lett. Vol. 66 (1991), p. 2980.

[21] C.C.Teng and A.F. Garito: Phys. Rev. B Vol. 28 (1983), p. 6766.

[22] M. Stahelin, D.M. Burland and J.E. Rice: Chem. Phys. Lett. Vol. 191 (1992), p. 245.

[23] J.L. Oudar: J. Chem. Phys. Vol. 67 (1977), p. 446.

[24] J.L. Oudar and D.S. Chemla : J. Chem. Phys. Vol. 66 (1977), p. 2664.

[25] J. Zyss and J.L. Oudar: Phys. Rev. A Vol. 26 (1982), p. 2016.

[26] M.M.M. Raposo, A.M.R.C. Sousa, A.M.C. Fonseca and G. Kirsch: Mater. Sci. Forum Vol. 514-516 (2006), p. 103. 